\title{
Simulate New Near Equatorial Satellite System by a Novel Multi-Fields and Purposes Remote Sensing Goniometer
}

\author{
Hayder Dibs ${ }^{1,2}$, Shattri Mansor ${ }^{2}$, Noordin Ahmadb ${ }^{2,3}$, Nadhir Al-Ansari ${ }^{*}$ \\ ${ }^{1}$ Hydraulic Structures Department, Faculty of Water Resources Engineering, Al-Qasim Green University, Al-Qasim, Iraq \\ ${ }^{2}$ Geospatial Information Science Research Centre, Faculty of Engineering, University Putra Malaysia, Level 6, Tower Block, \\ Selangor, Malaysia \\ ${ }^{3}$ National Space Agency Malaysia (ANGKASA), Kementerian Sains, Teknologi dan Inovasi, Pusat Angkasa Negara, Lot 2233, Jalan \\ Turi, Kg. Sg. Lang, Banting, Malaysia \\ ${ }^{4}$ Department of Civil Environmental and Natural Resources Engineering, Lulea University of Technology, Lulea, Sweden \\ Email: Dr.hayderdibs@wrec.uoqasim.edu.iq, haiderdibs@gmal.com, shattri@gmail.com,noordin.ahmad@gmail.com, \\ *nadhir.alansari@ltu.se
}

How to cite this paper: Dibs, H., Mansor, S., Ahmadb, N. and Al-Ansari, N. (2020) Simulate New Near Equatorial Satellite System by a Novel Multi-Fields and Purposes Remote Sensing Goniometer. Engineering, 12, 325-346.

https://doi.org/10.4236/eng.2020.126026

Received: May 17, 2020

Accepted: June 14, 2020

Published: June 17, 2020

Copyright $\odot 2020$ by author(s) and Scientific Research Publishing Inc. This work is licensed under the Creative Commons Attribution International License (CC BY 4.0).

http://creativecommons.org/licenses/by/4.0/ (c) (i) Open Access

\begin{abstract}
Researchers in the remote sensing field use different types of images from satellite systems and simulator devices, such as goniometers. However, no device can simulate the new generation of optical satellite system called near-equatorial satellite system to perform different kinds of remote sensing applications in equatorial regions. This study proposed a newly invented laboratory and fieldwork goniometer designed to simulate and capture intensity variation and measure the bidirectional spectral reflectance of earth surface. The proposed goniometer is a multi-purpose and multi-field device. It is able to simulate different satellite systems and measure the intensity variation and spectral reflectance of earth's surface features with freely azimuth and zenith angles of sensors and illumination source in fieldwork and/or laboratory. However, the system of invention is focusing on specific satellite orbital to work with the parameters and properties of $\mathrm{NEqO}$ satellite system in order to obtain $\mathrm{NEqO}$ system imagery for performing different applications such as geometric correction, relative radiometric normalization and change detection for future work. The significant of this invention is that most of the invented goniometers of remote sensing are able to work just in field or just in laboratory and use, carry just optical sensor or hyperspectral sensor. Specifically, our invention can do all these functions that are not available in existing goniometers. The proposed device offers several advantages, namely, high measurement speed, flexibility, low cost, efficiency, and possible measurement depending on the free zenith/azimuth angles of sensors and illumina-
\end{abstract}


tion sources. The proposed goniometer includes ten parts, and two different sensors (optical and hyperspectral).

\section{Keywords}

Near-Equatorial Satellite System, Remote Sensing Goniometer, Low-Cost Goniometer, Optical Sensor, Hyperspectral Sensor

\section{Introduction}

The near equatorial orbit $(\mathrm{NEqO})$ satellite system is a new generation of optical satellite that unlike polar satellite system, it does not have a fixed row and path in its equatorial travel. It will pass over all equatorial areas for 14 times a day. Its imagery will have differences in illumination, viewing points, capture time, solar and satellite zenith and azimuth angles, and attitude (roll, yaw, and pitch) of the satellite each capturing time. All these conditions together make $\mathrm{NEqO}$ satellite imagery unusable [1] [2]. So, we need a new device able to simulate the NEqO system imagery to overcome with these difficulties before launching the new satellite system of NEqO [3] [4] [5] [6]. Many different types of field and/or laboratory goniometers can measure anisotropic reflectance. However, most goniometers used in the field and/or in laboratories to measure the bidirectional reflectance of earth surface features are built for remote sensing applications and are equipped with hyperspectral sensors only [1]-[9]. These devices simulate polar satellite systems and are unsuitable for the new generation of the NEqO satellite systems that capture images and spectral reflectance in the field and/or in laboratories [3] [4] [7] [10] [11]. Finding an optical simulation system (a goniometer) that can measure the anisotropic reflectance distributed on earth surface features for use in the field and/or in laboratories is difficult. Different simulation systems can be used to simulate anisotropic reflectance. However, most of these systems focus on using the spectral reflectance of surface features by launching the spectro-radiometers of the simulation devices. There is no device focusing on using optical multi-spectral and/ or optical hyperspectral sensor and making the goniometer satisfactory to simulate the new generation of satellite system called NEqO system [3] [4] [11].

\section{Background}

Different types of field and laboratory goniometers are used to measure the variation in the spectral reflectance of earth surface features. Field and laboratory goniometers have certain specifications. Laboratory goniometers have the advantage of constant illumination and neglectable atmospheric disturbances [11] [12]. However, artificial light sources are usually less parallel and less homogeneous than clear sky solar illumination. Currently, no system combines field and laboratory measurements obtained using different sensors [4] [12]. For operational earth observation applications, multi-temporal data usage is required to 
increase the number of observations, particularly in regions with frequent cloud cover [13]. This requirement increases the need for high-quality time-series data for activity monitoring. Information on the bidirectional reflectance distribution function (BRDF) of different earth surface features is relevant in normalizing the images taken under different illumination and/or viewing conditions [14]. Nevertheless, multi-angular observations provide additional information to improve the accuracy of retrieved products [13] [15] [16].

Although field observations are extremely useful, most researchers in the field are faced with the problem of recording pure reflectance to fit BRDF models. This problem can be addressed with multi-directional reflectance measurements acquired under controlled laboratory conditions, through which a large amount of directions can be sampled [3] [4]. A number of laboratory goniometers have been invented Sandmeier et al. invented the European goniometric facility of the Joint Research Centre. At the University of Zurich [1], Schopfer et al. invented a goniometer called a field goniometer system (FIGOS) that can also be used in the laboratory [17]. The Sandmeier field goniometer (SFG) of NASA Ames was developed on the basis of FIGOS [18]. Coburn et al. [15] invented a goniometer system called the ULGS at the University of Lethbridge, and Biliouris et al. [19] built a goniometer system called the compact laboratory spectro-goniometer (CLabSpeG) at the Catholic University Leuven. Several laboratory remote sensing goniometers can be utilized in the field. Laboratory goniometer systems have unique specifications that make them better than fieldwork goniometers; 1) Limited in the flexibility of the system in terms of hemisphere size and measurement positions, and 2) Taking a long time for sampling a full hemisphere, which causes problems for plants susceptible to changes in leaf angle and orientation due to changes in turgor in the plant tissue and changes in soil due to dehydration [16] [18]. All these goniometers measure reflectance anisotropy; we are aware of only one system (goniometer) that can measure the anisotropy of reflectance both of spectral reflectance (using spectro-radiometer device) and intensity variation (multi-spectral optical device) in field and laboratory.

The aim of this study is, because of the $\mathrm{NEqO}$ satellite does not have fixed row and path like other satellite systems, so it is imagery will have no band to band registration, no matching in geometric and radiometric sides, also there is no other satellite systems like this the new generation can we use their imagery to do analyzing and processing for different researches [6] [7]. Therefore, this study aim is to describe in details the design and implementation stages of a new invented simulating goniometer to simulate the NEqO satellite system. This work also presents the components of the proposed system and the concept of using this system in both the field and the laboratory.

\section{Method and Materials}

The goniometer of the NEqO system images and apparatus will use to acquire the NEqO system images and capture images at different azimuth and zenith angles of the sensor and illumination source to a simulate the NEqO satellite 
system images. This device can be used to capture NEqO images from the field and/or in the laboratory. The images simulated with the goniometer can be captured by optical and/or spectro-radiometer sensors. This condition means this device a comprehensive goniometer that can be employed to accomplish four tasks. The images captured with this device are suitable for the study and analysis of the radiometric measurements of the reflection behavior of earth surface features. The preferred embodiment of the proposed goniometer is described individually and in any combination, as shown in Figures 1-8. The NEqO goniometer was made by following stages:

\subsection{Goniometer Design and Description}

The NEqO goniometer designing stage, it is start with using SolidWorks 2013 software environment in order to drawing the design. Figures 1-8 illustrate the design of all parts of the goniometer. Each part of this goniometer was drawn separately then collected together to manufacture it. The device part will describe in details in following sections.

\subsubsection{Rolling Azimuth Angle Circle}

The rolling azimuth angle is the main component of the simulation of the NEqO satellite system. It carries all the parts of the simulating $\mathrm{NEqO}$ satellite system. The rolling azimuth angle allows the use of full azimuth angles in capturing the simulated $\mathrm{NEqO}$ satellite images. In accordance with the preferred embodiment of the goniometer, the roll azimuth angle is set to a full circle divided from $0^{\circ}$ to $360^{\circ}$ to represent and use the full azimuth angle at intervals of $10^{\circ}$. These

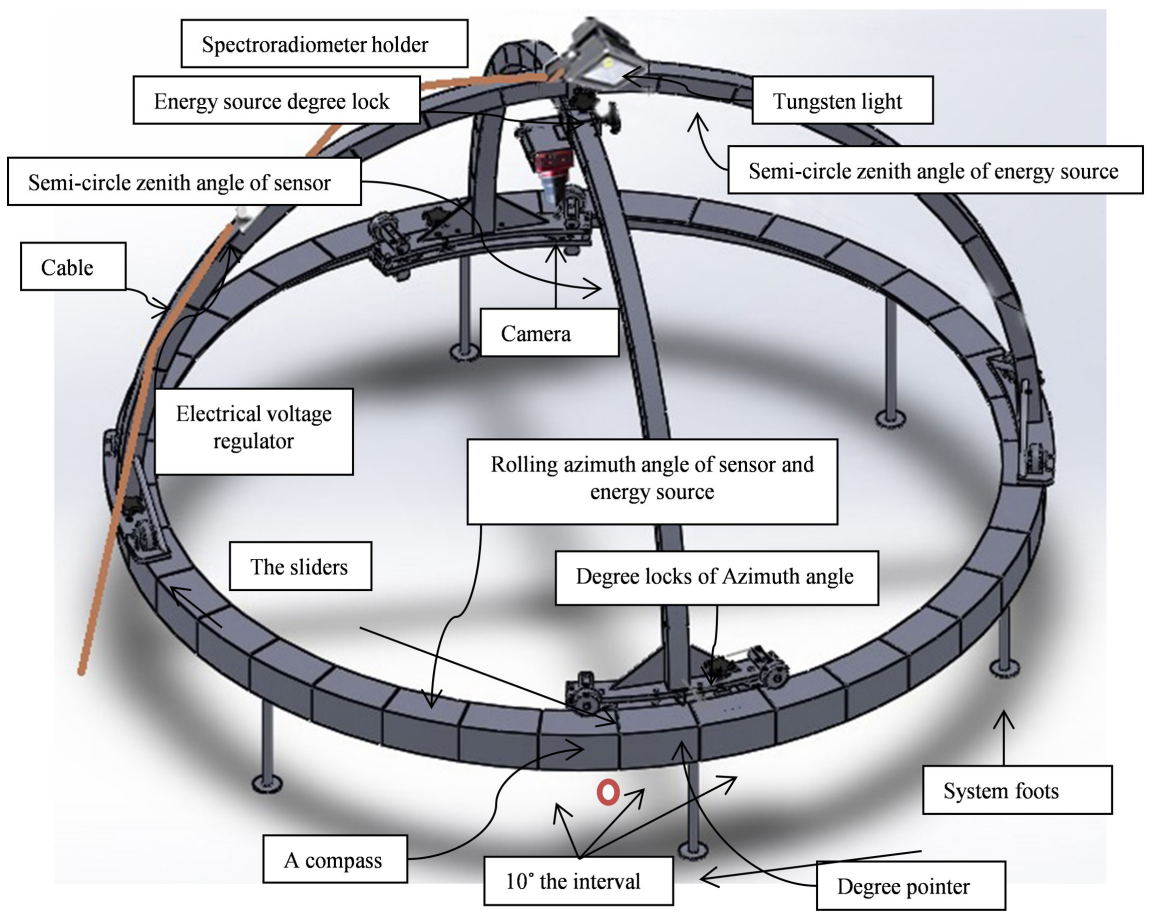

Figure 1. The simulating NEqO field and laboratory system design. 


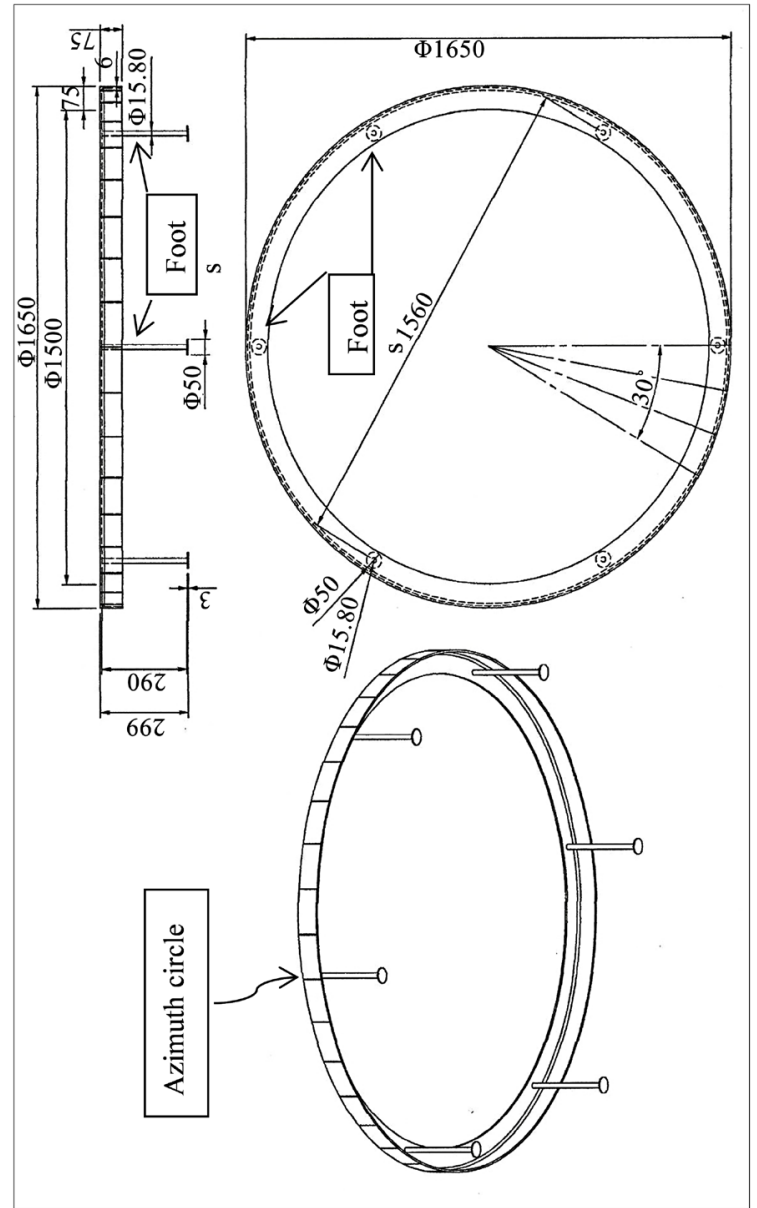

Figure 2. Rolling azimuth circle part.

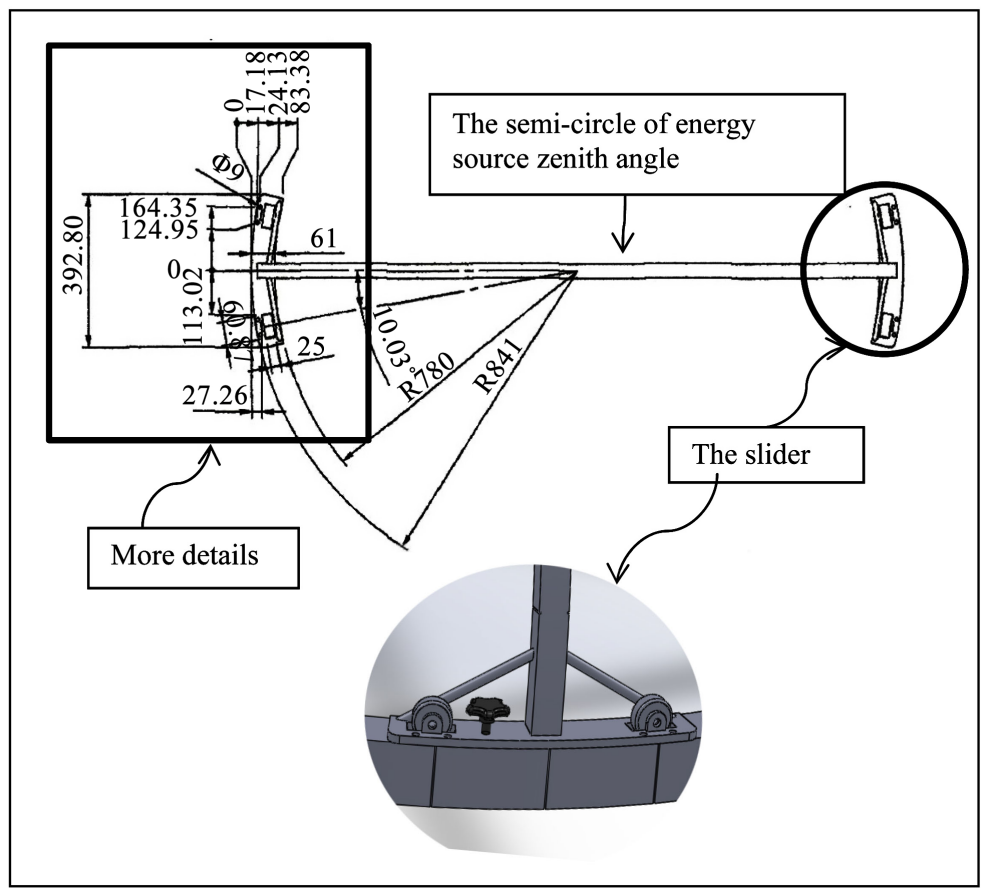

Figure 3. The semi-circle of illumination source zenith angle. 


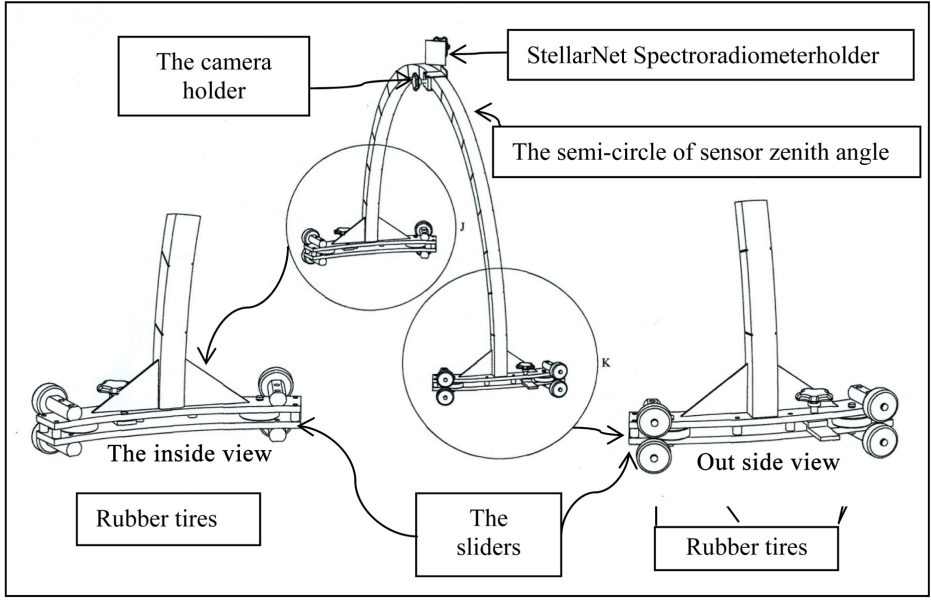

Figure 4. Semi-circular zenith angle of the sensors and sliders.

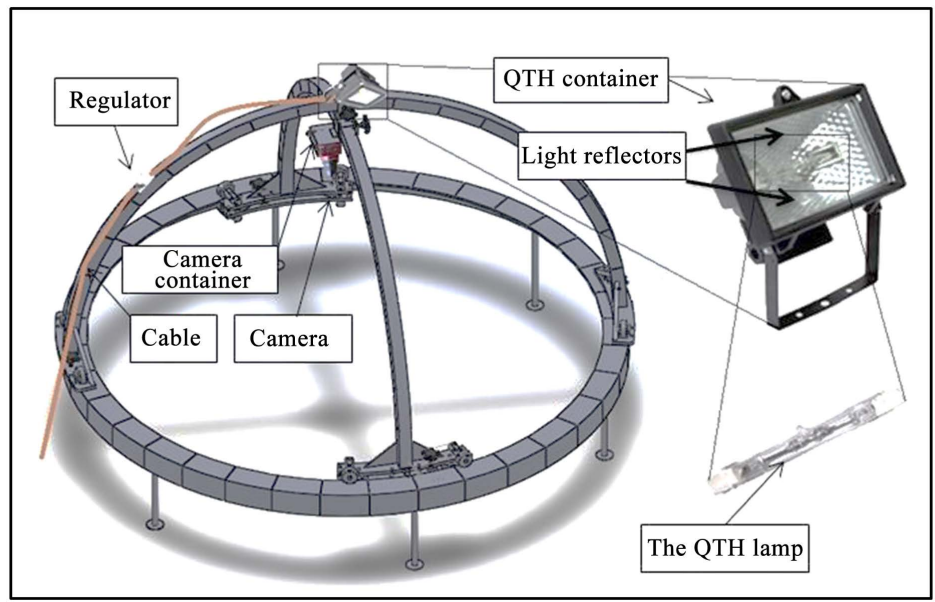

Figure 5. Lamp of illumination source.

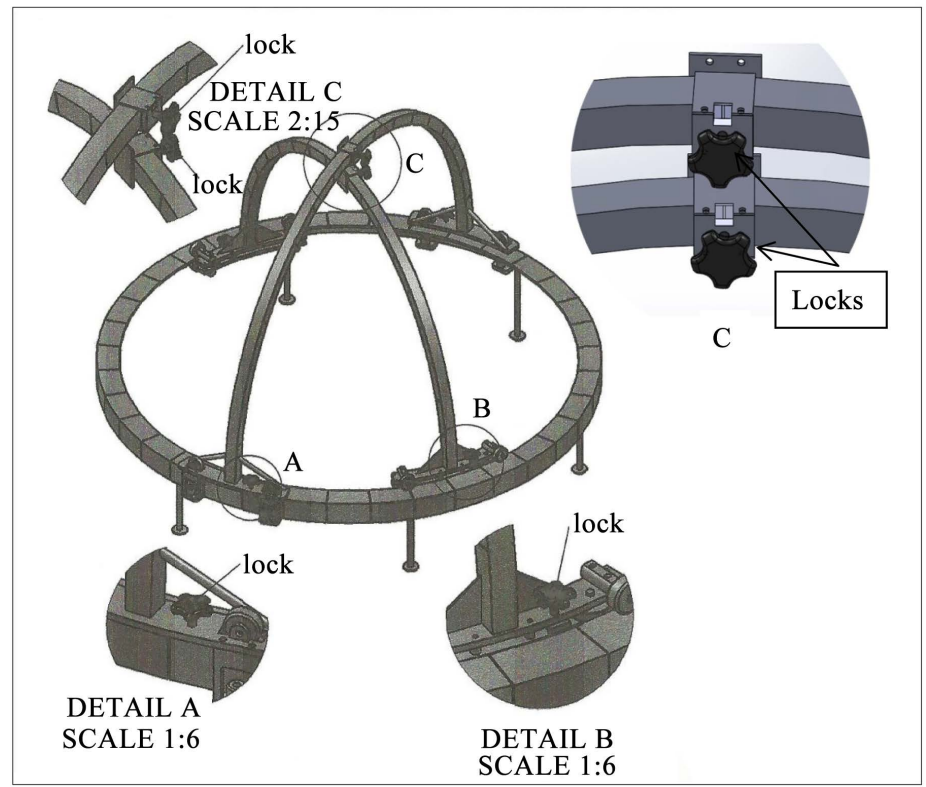

Figure 6. Degree locks of azimuth and zenith angles. 


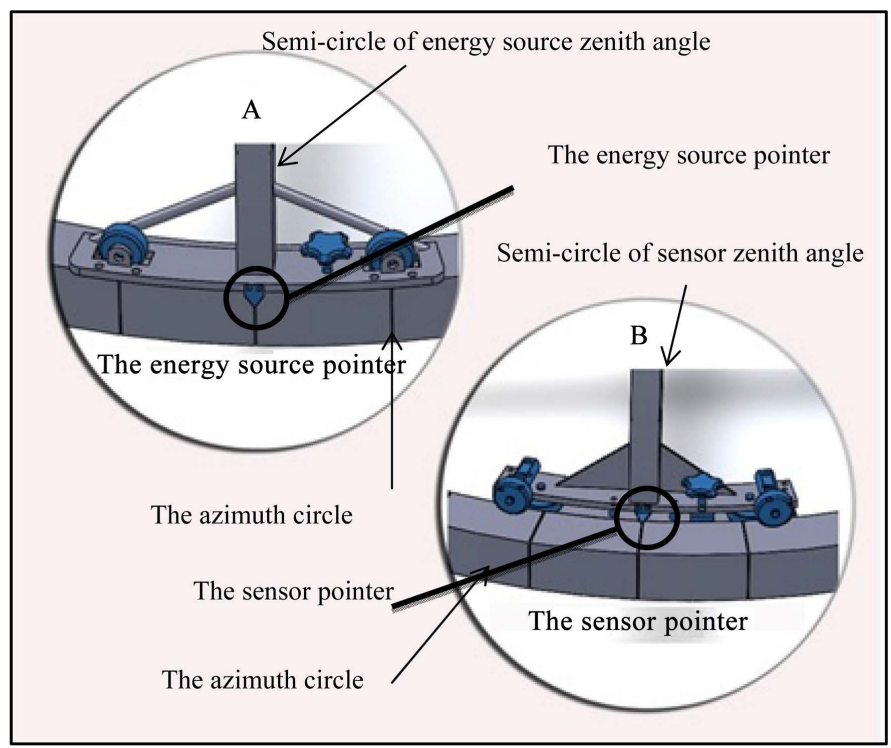

Figure 7. Sensor and illumination source pointers and their locations.

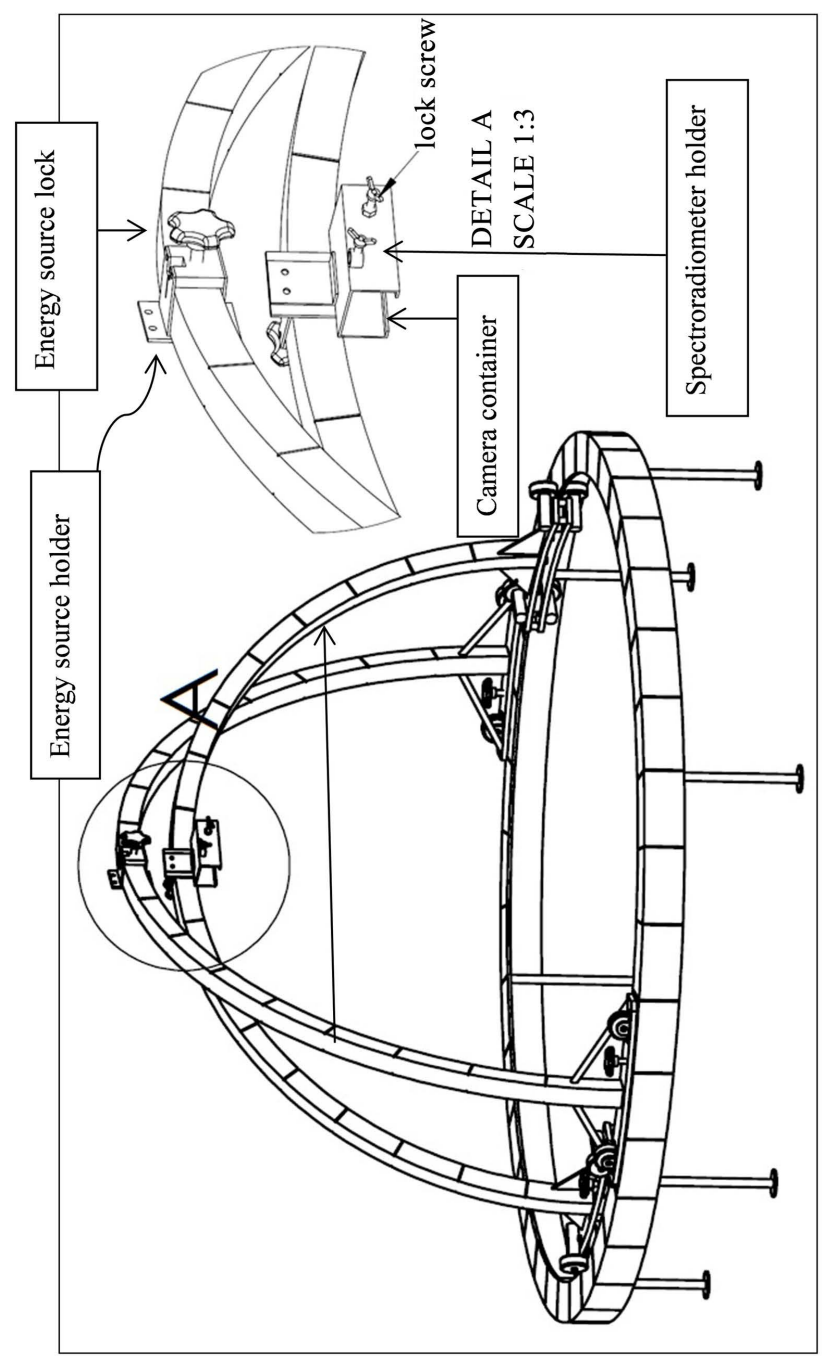

Figure 8. Holder of portable Stellar Net spectro-radiometer device. 
intervals are marked with stacker numbers to guide the users in capturing the $\mathrm{NEqO}$ images at the different azimuth angles of both the optical sensor and illumination source.

The rolling azimuth angle of the goniometer of the $\mathrm{NEqO}$ satellite system has six feet that stand on the ground. The position between each foot and the previous and/or next one is $60^{\circ}$ of the rolling azimuth angle to make the standing of the rolling azimuth angle stable on the ground and to distribute the weights of the all parts of the goniometer equally onto the feet of the roll azimuth angle. Each foot has sufficient distance from the ground. A height of $299 \mathrm{~mm}$ is selected to keep the optical sensor and portable spectro-radiometer sensor close to the surface features that users wish to capture as $\mathrm{NEqO}$ images.

The zero mark of the rolling azimuth angle is used with the aid of the compass to direct the zero mark to the North Pole, provide all the measurements with the same orientation as the real $\mathrm{NEqO}$ system, and help users to determine the real azimuth angles of the illumination source and sensor. The material of the rolling azimuth angle is stainless steel because the device focuses on simulating $\mathrm{NEqO}$ satellite images and can be used in the field and/or in the laboratory in equatorial regions. If the purpose requires field (outdoor) use, most near-equatorial regions around the world can utilize the proposed goniometer. These regions have large amounts of rainfall, high temperature, and high humidity. These climate factors and others would cause the goniometer to erode or become damaged if it were made from materials other than steel. The shape of the rolling azimuth angle of the goniometer is a full circle instead of a semi-circle and/or a quarter-circle so as to freely use different sensor and illumination source azimuth angles from $0^{\circ}$ to $360^{\circ}$, support the structure of the goniometer of the simulating $\mathrm{NEqO}$ satellite system, and make the structure of the goniometer stronger. Figure 2 shows the top, side and front view of the rolling azimuth angle circle, as well as its other details, such as the internal and external diameters and the heights.

\subsubsection{Semi-Circle of Illumination Source Zenith Angle}

This part of the goniometer system identifies the zenith angles of the launched illumination source as shows in Figure 1. The semi-circle of the illumination source zenith angle of the goniometer of the $\mathrm{NEqO}$ satellite system contains the illumination source, electrical regulator, illumination source holder, zenith angle lock, zenith angle pointer, electrical cable, and two sliders (each one is positioned at the end of the semi-circular zenith angle of the illumination source). Each slider has one azimuth angle lock and six plastic wheels. One azimuth pointer is positioned at the center of one of the sliders and illumination source reflectors. The semi-circular zenith angle of the illumination source is divided into $180^{\circ}$ angles to allow users to maximize the full zenith angles. The semi-circular shape of the zenith angle allows it to be used freely in both sides (forward and backward) and supports and strengthens the structure of the goniometer. The electrical regulator is positioned at the end of one slider to facilitate the movement of the illumination source along the semi-circular zenith angle. An elec- 
trical cable connects the electrical regulator and the illumination source to ensure that the electricity originates from the power supply and then moves to the electrical regulator before reaching the illumination source. Each slider is fixed in one end side of this part.

The semi-circular zenith angle of the illumination source can be modified according to user requirements by rotating it up to $360^{\circ}$ through its sliders above the roll azimuth angle. In accordance with the preferred embodiment, the semi-circular zenith angle of the illumination source is divided from $0^{\circ}$ to $180^{\circ}$ at intervals of $10^{\circ}$ to allow the illumination source to move from $0^{\circ}$ to $180^{\circ}$. This feature is taken advantage of when capturing $\mathrm{NEqO}$ images at different zenith angles of the illumination source. The material of the semi-circle circular zenith angle of the illumination source is stainless steel to allow its use in near-equatorial regions. These regions have large amounts of rainfall and high humidity, which can cause the goniometer to erode. The illumination source holder is positioned on the semi-circular zenith angle of the illumination source and is used to hold the illumination source.

The illumination source holder comprises illumination source reflectors to diffuse the illumination throughout the capturing site and reflect the illumination during the capturing of the $\mathrm{NEqO}$ system images. The direction and materials of the illumination source holder and illumination source reflectors are extremely important in image capturing and are better than their counterparts in other devices. The illumination source holder has a zenith angle lock to allow users to lock in the zenith angle they want to position the illumination source at. The zenith angle pointer of the illumination source holder helps users determine the zenith angle of the illumination source and lock it by using the illumination source lock.

Each of the slider has one azimuth angle lock. This azimuth lock enables users to lock the semi-circular zenith angle of the illumination source at any preferred azimuth angle. Each slider also has six plastic wheels for the easy, fast, and flexible rotation of the semi-circular zenith angle of the illumination source along the rolling azimuth angle

The six wheels are made of plastic to reduce the friction between the semi-circular zenith angle and the rolling azimuth angle. This condition allows the flexible and easy rotation of the semi-circular zenith angle. It also protects the device for a long time and increases its efficiency. The cost may also be reduced if the wheels are built using another material, such as iron. The azimuth angle pointer is positioned on one side of the semi-circular zenith angle and enables user to determine the specific azimuth angle that would meet their desired position for the illumination source. All the locks of the semi-circle circular zenith angle of the illumination source, such as the two azimuth angle locks, are made of plastic. This material is better than others, such as iron and copper, especially if the goniometer of the $\mathrm{NEqO}$ satellite system needs to be used in the field. Materials such as iron and copper could reach high temperatures, which could in turn pose a hazard to users. Moreover, plastic is cheaper than other 
materials. Figure 3 presents the drawings of the sliders fixed in the end part of the semi-circular zenith angle.

\subsubsection{Semi-Circular Zenith Angle of the Sensors}

This part of the goniometer will describes the zenith angles of the sensors, as shown in Figure 1. Accordingly, the semi-circular zenith angle of the sensors covers each of the sensor holders, the optical sensor, the zenith angle lock, the zenith angle pointer, and two sliders (each is positioned in the ends of the semi-circular zenith angle of the sensors). The semi-circular zenith angle of the sensors has one azimuth pointer, and each slider has one azimuth angle lock and six plastic wheels. The semi-circular zenith angle is divided into $180^{\circ}$ to allow users to maximize the full zenith angles of the sensor, including its forward and backward features. The semi-circular shape of the zenith angle is better than a quarter-circular shape for it allows the free use of both of its sides (forward and backward) and supports and strengthens the structure of the goniometer. The semi-circular zenith angle of the sensors can be modified according to user requirements by rotating it up to $360^{\circ}$ through its sliders above the roll azimuth angle. In accordance with the preferred embodiment, the semi-circular zenith angle of the sensors is divided from $0^{\circ}$ to $180^{\circ}$ at intervals of $10^{\circ}$ to make the sensor move from $0^{\circ}$ to $180^{\circ}$ along the semi-circle of the sensor zenith angle. This capability is then utilized to capture $\mathrm{NEqO}$ images at different illumination source zenith angles.

The material of the semi-circle circular zenith angle of the sensors is stainless steel to allow its use in near-equatorial regions. These regions have large amounts of rainfall and high humidity, which can cause the goniometer to erode. The sensor holders are positioned on the semi-circular zenith angle of the sensors to hold the optical sensor and/or portable spectro-radiometer for capturing $\mathrm{NEqO}$ system images and/or collecting the spectral reflectance of different earth surface features distributed in the study area at different zenith and azimuth angles. The optical sensor can capture $\mathrm{NEqO}$ system images at any zenith angle with the use of the zenith angle pointer. This angle is then locked. Each slider has one azimuth angle lock. This azimuth lock enables users to lock the semi-circular zenith angle of the sensors at any preferred angle. Each slider also has six plastic wheels for the easy, fast, and flexible rotation of the semi-circular zenith angle of the sensors along the roll azimuth angle. The wheels are made of plastic to reduce the friction between the semi-circular zenith angle of the sensors and the roll azimuth angle. This condition allows the flexible and easy rotation of the semi-circular zenith angle. It also protects the device for a long time and increases its efficiency.

The cost may be reduced if it is built using another material, such as iron [19] [20]. The azimuth angle pointer is positioned on one side of the semi-circular zenith angle and enables users to determine the specific azimuth angle that would meet their desired position for the optical sensors. All the locks of the semi-circular zenith angle of the sensors, such as the two azimuth angle locks 
and the sensor zenith angle locks, are made of plastic. This material is cheaper and better than other materials, such as iron or copper, especially if the goniometer of the NEqO satellite system needs to be used in the field. Materials such as iron and copper could reach high temperatures, which could in turn pose a hazard to users. Figure 4 presents the drawings of the sliders fixed in the end of the semi-circular zenith angle of the sensors. The diameter of the semi-circular zenith angle of the sensors is less than that of the illumination source for convenient rotation Figure 1. The semi-circular zenith angle of the illumination source can be easily removed when the goniometer system is used in fieldwork data collection without interfering with the parts of the illumination source and preventing the capture of falling shadows.

\subsubsection{Optical and Hyperspectral Sensors}

The optical sensor of the goniometer of the NEqO satellite system is an optical camera utilized to capture the visible parts of a spectrum. The camera located in the semi-circular zenith angle of the sensors and held by the sensor holder is used to capture the simulation of the NEqO system images for the study of the variation in the radiometric reflectance originating from the different zenith and azimuth angles. The camera can capture images at any zenith angle along the semi-circular zenith angle of the sensors (from $0^{\circ}$ to $180^{\circ}$ ) through the zenith angle pointer and then locks on the specific zenith angle through the use of the zenith angle locks. The user can also determine the azimuth angle of the camera for image capture by using the azimuth angle pointer. The semi-circular zenith angle of the sensors can rotate over the roll azimuth circle from $0^{\circ}$ to $360^{\circ}$. This condition allows users to obtain images from any azimuth and zenith angles of the sensors depending on their application. In the current work, we utilize a Canon SX 700 H Power Shot to capture the images. In lieu of a camera, a portable Stellar Net spectro-radiometer joined by a special holder to the semi-circular zenith angle of the sensors can be used to measure the spectral reflectance of the earth surface features distributed in the study area. This spectral reflectance can be used to study and analyze the BRDF. The wavelength range of the portable Stellar Net spectro-radiometer is 400 to $1100 \mathrm{~nm}$. This camera can capture images in JPEG format with red, green, and blue bands. The selection of the optical sensor is based on camera specifications. We found that this camera is better than other cameras. Solar illumination is used to capture fieldwork (outdoor) images. For images captured in the laboratory, the built-in light of the camera is replaced with another illumination source, as described in the next paragraph.

\subsubsection{Illumination Source}

The illumination source is positioned in the semi-circular zenith angle of the illumination source. The energy source of this goniometer system is a 150 -watt QTH lamp that functions as an artificial light source. The QTH operates at 220 V. QTH lamps are visible and near-infrared light sources. Therefore, they can capture visible bands by using the camera mentioned above or near-infrared 
bands by incorporating the portable spectro-radiometer device into the semi-circular zenith angle of the illumination source. The QTH has a smooth spectral curve and stable output.

The illumination is constant, stable, and diffused. The QTH is surrounded with sufficient reflectors to diffuse light throughout the study site. Users can position the QTH at any azimuth and zenith angles to capture images at the different azimuth $\left(0^{\circ}\right.$ to $\left.360^{\circ}\right)$ and zenith $\left(0^{\circ}\right.$ to $\left.180^{\circ}\right)$ angles by using the zenith angle pointer to determine the zenith angle of the QTH and then by using the zenith angle lock. Users can also specify the zenith angle from $0^{\circ}$ to $180^{\circ}$. However, to determine the azimuth angle of the QTH, the semi-circular zenith angle of the illumination source must be rotated over the roll azimuth angle of the goniometer. The specific azimuth angle is determined with the azimuth angle pointer, and locking is achieved with the azimuth angle locks of the sliders.

The power of the illumination source (QTH) is 150 watts according to the height of the goniometer $(104.9 \mathrm{~mm})$. The light of the QTH must be equally diffused. All the sites must have the same light intensity. If more than 150 watts of light intensity is used, then all the captured images become extremely bright. If the power of the illumination source (QTH) is small, then the simulation of the $\mathrm{NEqO}$ system images becomes unsatisfactory because all the images appear with high contrast. Figure 5 describes the illumination source and its holder used in this study.

\subsubsection{Electrical Voltage Regulator}

The electrical voltage regulator is positioned at the end of the semi-circular zenith angle of the illumination source. It is used as the lighting control system of the illumination source. The electrical voltage regulator is connected to an electrical power supply with $220 \mathrm{~V}$ and to the illumination source by an electrical cable. The electrical voltage regulator is divided into degrees to change the illumination intensity during image capture.

The electrical voltage regulator is used only in the laboratory. The regulator is important to the system because it changes the illumination intensity for each captured image to simulate the $\mathrm{NEqO}$ images. Consequently, images from the same area are captured at different illuminations and contrast levels. This condition is useful in performing relative radiometric normalization and change detection on these [3] [4] [16] [18] [19] [20]. The electrical voltage regulator is divided into divisions, and each number corresponds to different light intensities to allow modifications.

\subsubsection{Compass}

The compass of the goniometer of the $\mathrm{NEqO}$ system is used in the goniometer design. This small compass is positioned in the semi-circular zenith angle of the sensors. The uses of the compass are as follows.

1) The compass is used in laboratory work to adjust and ensure that the zero mark of the roll azimuth angle is directed toward the North Pole (magnetic north pole) and to position the zero mark of the roll azimuth angle opposite the 
North Pole to allow users to determine the azimuth angle of the goniometer, determine the azimuth angles of the sensors and illumination source, and capture images on the basis of the azimuth angles of both the sensors and illumination source.

2) The compass is used in fieldwork to adjust and ensure that the zero mark of the roll azimuth angle is directed toward the magnetic North Pole. In this way, users can achieve their desired azimuth angles for the sensors used to capture images.

\subsubsection{Degree Locks of the Semi-Circular Zenith Angles}

One of the significant parts of the proposed goniometer is the degree locks. Six locks are launched and integrated to this system. The semi-circular zenith angles of the sensors and illumination source both have two degree locks. This feature enables users to select the specific azimuth angles of the sensors and illumination source and then lock such azimuth angles to capture images. Another two degree locks are launched to the sensor container (camera container) and the illumination source. Each container has one lock to determine the specific zenith angles of the sensors and illumination source and then capture images at these specific zenith angles. Figure 6 shows the six locks of each of the two semi-circular zenith angles of the sensor container and illumination source. In Figure 6, the lock is divided into " $A$ ", "B", and "C".

\subsubsection{Azimuth Angle Degree Pointers}

Two pointers are used in the proposed device. The benefit of using pointers lies in determining the azimuth angles of both the sensors and the illumination source for capturing images and then launching the locks. Without these pointers, the azimuth angles of the sensors and illumination source will change while capturing images. Therefore, two pointers are used to address this issue. The first pointer is launched and joined at the semi-circular zenith angle of the sensors, and the second pointer is launched to the semi-circular zenith angle of the illumination source. Figure 7 illustrates the pointers and their location in the device. Part " $\mathrm{A}$ " describes the sensor pointer, and part "B" demonstrates the illumination source pointer.

\subsubsection{Stellar Net Spectroradiometer Holders}

The sensor holders consist of an optical sensor container, the holder of the portable spectro-radiometer sensor, and an optical sensor lock. The sensor holders are positioned on the semi-circular zenith angle of the sensors. The sensor holders allow the use of the optical sensor through the optical sensor container and/or the portable spectro-radiometer sensor. The holder of the portable spectro-radiometer sensor captures and measures the images and spectral reflectance of earth surface features. The optical sensor lock enables users to utilize the different sizes of the optical sensor. Changing the optical sensor requires no change in the entire goniometer. The goniometer of the $\mathrm{NEqO}$ system needs no modification when another optical sensor is used. The optical sensor lock re- 
duces the cost and increases the efficiency and speed of the goniometer. The holder of the portable spectro-radiometer sensor provides users the opportunity to select the optical sensor and/or the portable spectro-radiometer sensor for capturing and measuring the radiometric reflectance of the $\mathrm{NEqO}$ system. In this way, the proposed device can be used to collect hyperspectral data or images. However, existing goniometers have either a hyperspectral sensor or an optical sensor, and none is equipped [3] [4] [11]. The goniometer of the NEqO system designed for use in both the laboratory and the field is equipped with optical and hyperspectral sensors.

This goniometer is built to simulate $\mathrm{NEqO}$ system images. It can simulate multi-sensor systems, geostationary satellite systems, polar satellite systems, and any other systems. Therefore, it can be used in different remote sensing applications. In this work, our focus is on the use of the proposed device to simulate the NEqO system.

Items (1) and (2) above indicate that the goniometer of the $\mathrm{NEqO}$ system is cheap, suitable, and easy to use. The diameter of the external and internal holders are 15 and $10 \mathrm{~mm}$, respectively, and their heights are both $5 \mathrm{~mm}$. Figure 8 shows the details of the holder in part " $\mathrm{A}$ ".

\subsection{Goniometer Manufacturing and Materials}

The second stage of building this goniometer was the manufacturing stage. After finished the designs of all goniometer' parts, we start to build up this device. The materials used to build the simulation NEqO device are stainless steel and plastic. The selection of these two material types is based on considerations of the environment, climate conditions, and user safety in tropical areas in equatorial regions [1] [3] [6] [10]. For example, the plastic material is used to build all the locks to protect the hands of users from high temperatures, especially when users need to use this invention outdoor for the entire day. The goniometer is made of stainless steel to protect it from damage and erosion in equatorial regions with high humidity, rainfall amount, and heat [11] [12]. However, using stainless steel makes the simulation NEqO system heavy; thus, the size of our design is small to reduce its weight for ease of transfer. All the steps of manufacturing were made on UPM University labs, Selangor, Malaysia. Figure 9 illustrates a part of manufacturing side of this goniometer.

\section{Collecting and Measurement Environment}

In this stage, the parts of this goniometer were collected together. On the other side, there is an issue should be discussed, it is the illumination distance (distance from the light source to the center of the target) in the laboratory and/or field is held constant at $104 \mathrm{~mm}$ [5] [7] [8]. The light equally covers the study area using the light reflectors, as described in Figure 5. To avoid unwanted scattering and its effects, the ground area of the laboratory is covered with wall panels painted with black non-reflective paint. Figure 10 illustrates the setup of the 


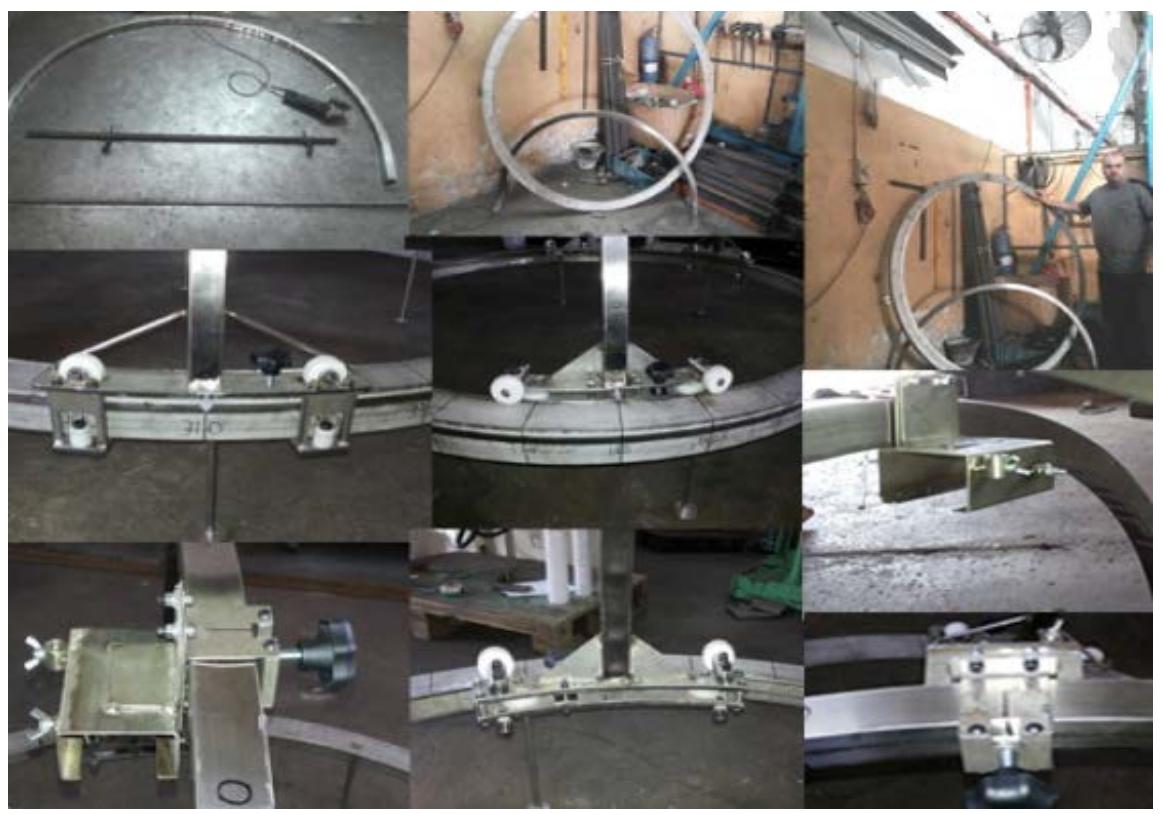

Figure 9. Manufacturing side of the goniometer.

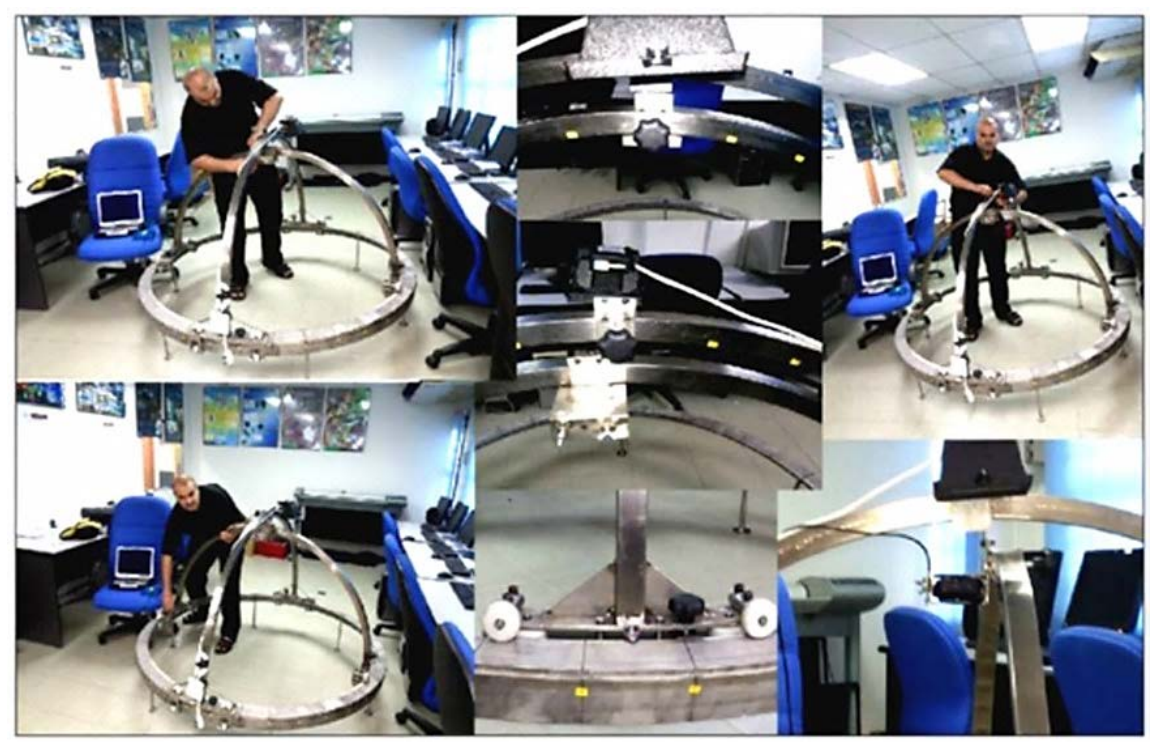

Figure 10. Setup of the goniometer.

goniometer system in the laboratory of the Geospatial Information Science Research Center (GISRC) of the University Putra Malaysia (UPM) after made all the components of this goniometer.

\section{Results and Discussion}

After finish designing, manufacturing and collecting goniometer parts, the goniometer became ready to test as indicates in Figure 11. The simulated NEqO system can capture images in any zenith and azimuth angle of the illumination source and sensors. Image capture can be achieved in the field (outdoor) or inside the laboratory by using an optical sensor (camera) or a portable 


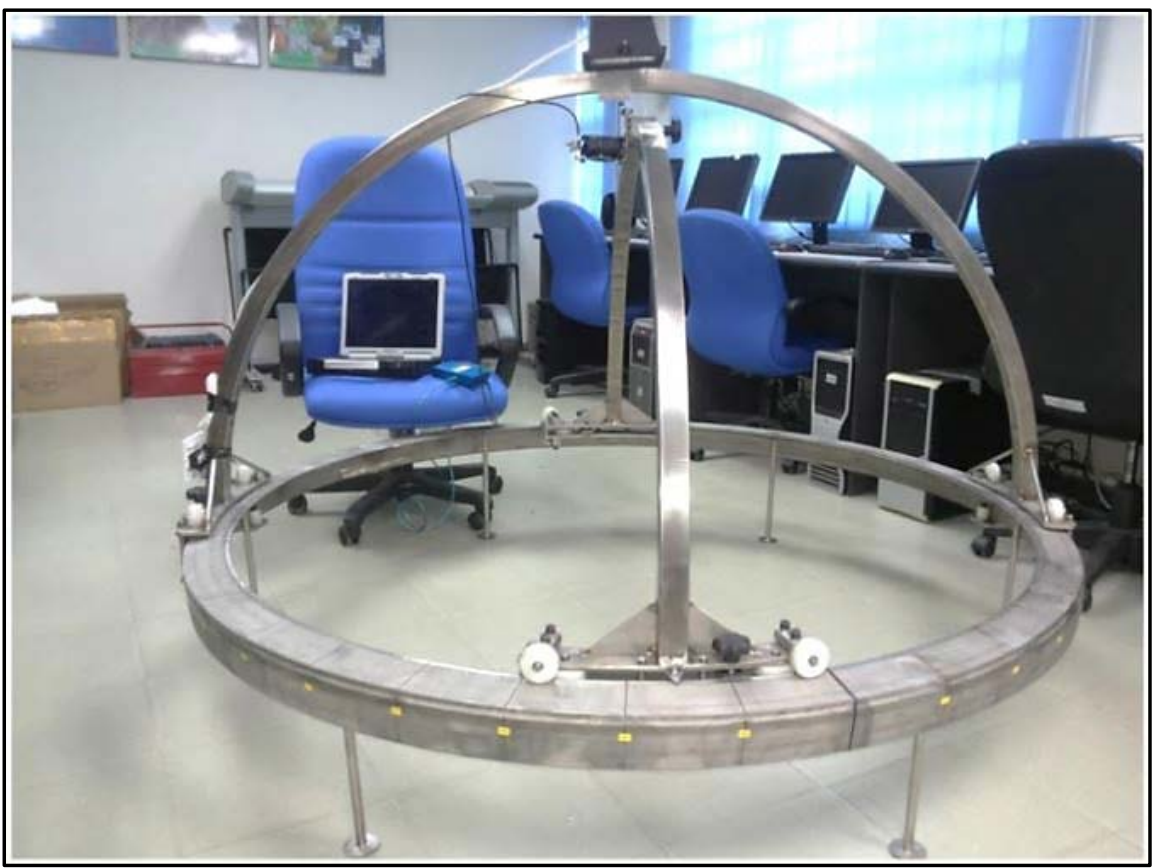

Figure 11. Invented remote sensing goniometer.

spectro-radiometer sensor. The system can be used to study the variation in the intensity values and spectral reflectance of the earth surface features distributed in the study area by capturing images through the camera sensor or by recording spectral reflectance through the portable Stellar Net spectro-radiometer. The designed device can be utilized to collect both field and laboratory data. No other device can perform these system tasks [3] [4] [11] [21] [22] [23] [24] [25].

In this stage, we will discuss how to use the manufactured goniometer for Capturing images. It can be achieved using these general steps.

1) The user determines where to use the device, that is, in the field or in the laboratory.

2) The user determines the use of the optical and/or hyperspectral sensor. The user then adjusts the circular roll azimuth angle toward the direction of the North Pole. The azimuth angle of the sensors and illumination source should be selected, and their respective azimuth locks should be used.

3) The user locates each sensor and illumination source in specific zenith angles in relation to each other. The user then utilizes the zenith angle locks of the sensors and illumination source.

4) The user can capture NEqO images with the optical sensor and record spectral reflectance with the portable spectro-radiometer sensor.

5) Steps (1) to (4) are repeated with some modifications in the azimuth and zenith angles of the sensors and illumination source to capture and collect new data. Table 1 shows the image capture specifications.

The proposed NEqO system was tested in the laboratory and in the field. We captured images by using the optical sensor. The captured images appeared to have the same problems and distortions as the real $\mathrm{NEqO}$ satellite images 
Table 1. The specifications of captured images in GISRC lab.

\begin{tabular}{cccc}
\hline Images no. & Light intensity & Location & $\begin{array}{c}\text { Sensor and light source } \\
\text { (azimuth and zenith angles) }\end{array}$ \\
\hline 1 & low & UPM University & zero \\
2 & moderate & UPM University & zero \\
3 & higher & UPM University & zero \\
Reference & The highest & UPM University & zero \\
4 & Less than & UPM University & zero \\
5 & moderate & UPM University & zero \\
6 & lowest & UPM University & zero \\
\hline
\end{tabular}

obtained from the NEqO Malaysian RazakSAT satellite. The system was easy to use and flexible. Table 1 shows the specifications of captured images inside the GISRC lab, UPM University, Malaysia. In 2015, however, Figure 12 illustrates the configuration of captured images regarding to the energy source and sensor configuration and locations. Next stage, was performed the Lab preparations to capture the images inside the UPM Lab as shown in Figure 13. This stage includes selecting different features to simulate the real world's features such as soil, plantation, stone, cements and Bricks. Authors selected all these features because most the real objects in real world have the same materials. Six images were captured have different reflectance to simulate the NEqO system after make everything in Lab ready and the images indicate in Figure 14. The sensor and energy source were fixed to be at Nadir for all captured images

Figure 12 demonstrates the geometric view of the sensors and illumination source, and Figure 13 and Figure 14 show six images captured to simulate the $\mathrm{NEqO}$ satellite system. The images were captured in the laboratory of the GISRC of the UPM University. Each image has different illuminations, which may be studied further for relative radiometric normalization. The captured images were tested and compared with real near-equatorial images from the RazakSAT satellite. The results revealed that the images produced by this goniometer have the same distortion, rotation, scaling, and illumination as near-equatorial images. After finished images capturing of the six images the lab, there was made a comparison between the proposed system with other goniometer systems. The outcomes of this comparison reveal that the designed NEqO system has the following features.

1) It can capture images in any zenith and azimuth angle of the illumination source and sensors.

2) It can capture images in the field (outdoor) or inside the laboratory, unlike others can perform measurements in fieldwork or laboratory [2] [26].

3) It is equipped with an optical sensor (camera) and a portable spectro-radiometer sensor. Most goniometers only have one sensor [23].

4) It can be used to study the intensity variation values and the spectral reflectance of the earth surface features distributed in the study area to capture images 


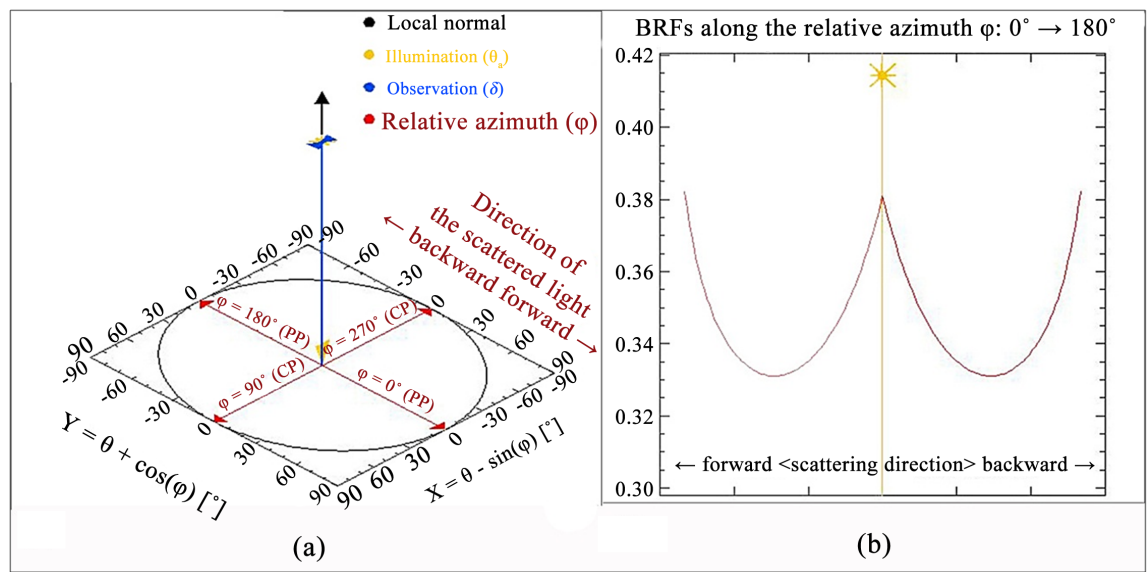

Figure 12. Configuration of captured images: (a) optical sensor and illumination in the azimuth and zenith angles and (b) scattering directions.

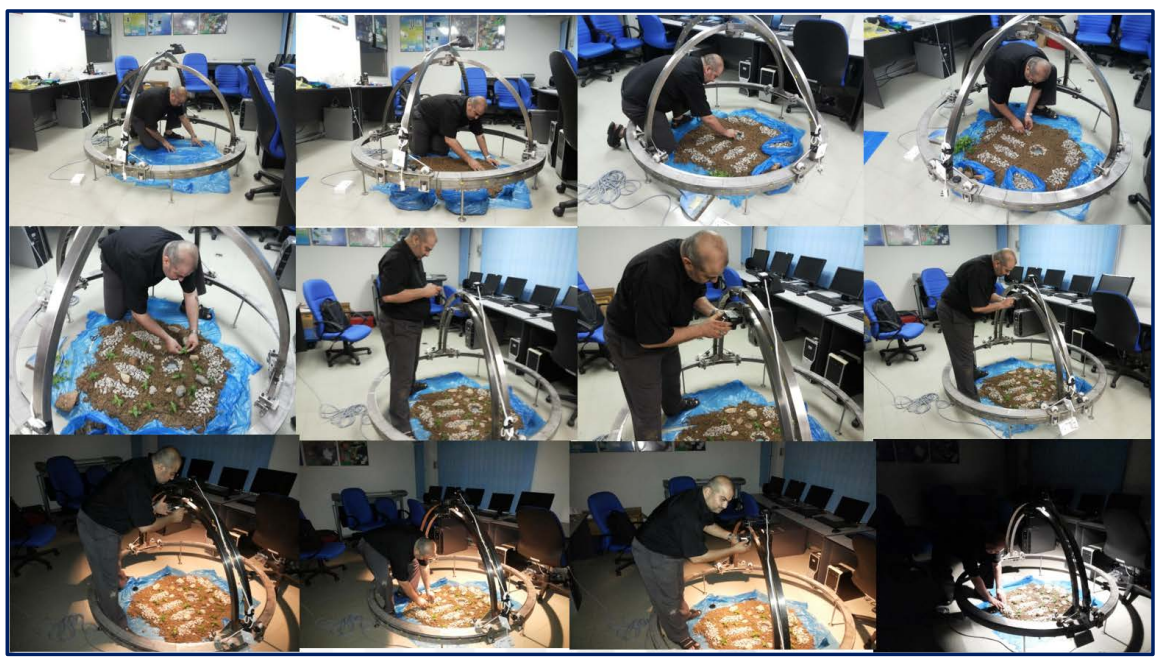

Figure 13. Preparation for collecting data inside UPM University Lab.
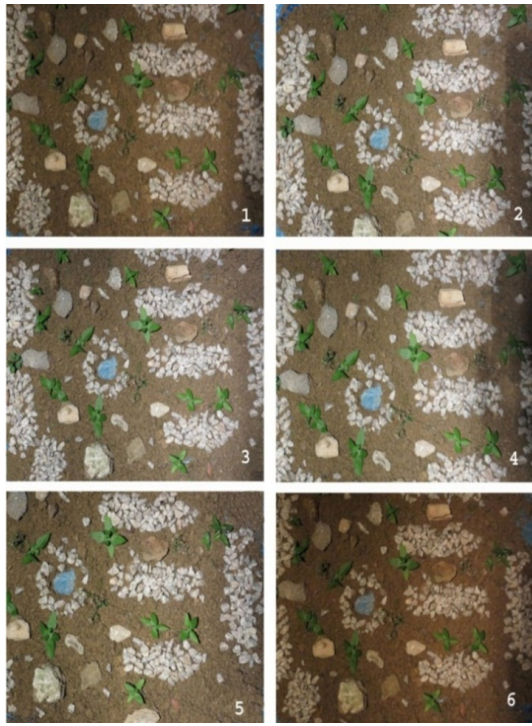

Figure 14. The collected images in different illumination inside UPM university lab. 
with the optical sensor or record the spectral reflectance by launching the portable Stellar Net spectro-radiometer.

5) It can be used to collect both field and laboratory data. No another device, including those proposed in previous studies can perform these tasks [3] [4] [11] [21] [22] [23] [24] [25].

6) It is easy to transport, sufficient, robust, inexpensive, and able to function optimally under difficult field conditions. Other devices are expensive and difficult to transport, especially with these devices fixed in the laboratory [23] [25].

7) It is weather-resistant because it is made of stainless steel.

8) It can be used to simulate different types of satellite systems on the basis of their launched orbital to capture images for the radiometric measurement of the BRDF of natural earth surface features, especially with anisotropic reflectance under freely selectable azimuth and zenith angles of the sensors and source illumination. Thus, it is a comprehensive goniometer. Other goniometers can perform only one task at a time [4] [23] [24] [25].

9) It can be used for research on academic society, remote sensing, space agencies, and astronomical field. Previous goniometers are limited to academic society [4] [25].

10) It easily maximizes the fully azimuth and zenith angles of the illumination source and sensors in fieldwork and/or in the laboratory. In other devices, the azimuth and zenith angles are fixed [21] [26] [27].

11) It has an adjustable optical container that allows the use of different types of optical sensors [4] [11] [24] [25] [26].

12) It has an adjustable hyperspectral sensor holder that allows the use of different types of spectro-radiometer sensors [4] [11] [24] [25] [26] [27].

\section{Conclusion}

The proposed device is a remote sensing goniometer for laboratory and field use that is designed and built to measure and capture the anisotropic reflectance behavior of earth surface features to simulate the $\mathrm{NEqO}$ system imagery by using the sun in the fieldwork or controlled illumination conditions at the laboratory. In addition to an optical sensor, this goniometer is equipped with a portable spectro-radiometer sensor to measure bi-directional spectral reflectance. The advantages of the device are the high measurement speed and the possibility of performing measurements depending on the freely zenith/azimuth angles of the sensors and source illumination. This device can be used in the fieldwork and/or laboratory with two different sensors (optical and portable hyperspectral) and is thus called a four-in-one device. The captured images were tested and compared with real near-equatorial images from the RazakSAT satellite. The results showed that the produced images of the proposed device have the same distortion, rotation, scaling, and illumination as near-equatorial images. The proposed goniometer simulates all types of satellite and airborne platforms, such as polar, geostationary, and multi-sensor satellite systems. Hence, this device is comprehensive. For our future work, we intend to use the simulated images to overcome 
the relative radiometric normalization problems in NEqO imagery. Furthermore, we plan to develop this goniometer to simulate $3 \mathrm{D}$ views of $\mathrm{NEqO}$ areas by launching a LIDAR sensor.

\section{Acknowledgements}

The authors are grateful to the Ministry of Technology, Science, and Innovation for providing the funds and supporting this invention. The authors would like to express their profound appreciation for and gratitude to the National Space Agency of Malaysia for providing the satellite imagery, as well as to the Malaysian Agency of Remote Sensing. Our appreciation also extends to the Malaysian Intellectual Patent Office for the patent of this goniometer (patent filing no.: IP 2015701847, filing date: 05/06/2015).

\section{Conflicts of Interest}

The authors declare no conflicts of interest regarding the publication of this paper.

\section{References}

[1] Dibs, H., Al-Janabi, A. and Gomes, G. (2017) Easy to Use Remote Sensing and GIS Analysis for Landslide Risk Assessment. Journal of University of Babylon for Engineering Sciences, 26, 42-54.

[2] Pegrum, B.H., Fox, N. and Milton, E. (2008) The NPL Gonio Radiometric Spectrometer System (GRASS). Proceedings of the Remote Sensing and Photogrammetry Society Conference: Measuring Change in the Earth System, University of Exeter, 15-17 September 2008, 1-3.

[3] Dibs, H., Mansor, S., Ahmad, N. and Pradhan, B. (2015) Band-to-Band Registration Model for Near-Equatorial Earth Observation Satellite Images with the Use of Automatic Control Point Extraction. International Journal of Remote Sensing, 36, 2184-2200. https://doi.org/10.1080/01431161.2015.1034891

[4] Marcel, B., Reinhold, P. and Birgit, H. (2013) A Manual Transportable Instrument Platform for Ground-Based Spectro-Directional Observations (ManTIS) and the Resultant Hyperspectral Field Goniometer System. Sensors (BaseI), 13, 16105-16128. https://doi.org/10.3390/s131216105

[5] Dibs, H., Mansor, S. and Ahmad, N. (2014) Registration Model for Near-Equatorial Earth Observation Satellite Images Using Automatic Extraction of Control Points. ISG Conferencel Kuala Lumpur, 1, 333-344.

[6] Dibs, H. and AL-Hedny, S. (2019) Detection Wetland Dehydration Extent with Multi-Temporal Remotely Sensed Data Using Remote Sensing Analysis and GIS Techniques. International Journal of Civil Engineering and Technology, 10, 143-154.

[7] Dibs, H. (2018) Comparison of Derived Indices and Unsupervised Classification for AL-Razaza Lake Dehydration Extent Using Multi-Temporal Satellite Data and Remote Sensing Analysis. Journal of Engineering and Applied Sciences, 13, 1-8.

[8] Abd, H. (2013) Feature Extraction and Based Pixel Classification for Estimation the Land Cover Thematic Map Using Hyperspectral Data. International Journal of Engineering Research and Applications, Coordinates Magazine, 3, 686-693.

[9] Dibs, H., Idrees, M.O., Saeidi, V. and Mansor, S. (2016) Automatic Keypoints Ex- 
traction from UAV Image with Refine and Improved Scale Invariant Features Transform (RI-SIFT). International Journal of Geoinformatics, 12, 51-58.

[10] Tal, F., Eyal, B.D. and Sagi, F. (2010) Correction of Reflectance Anisotropy: A Multi-Sensor Approach. International Journal of Remote Sensing, 31, 49-74. https://doi.org/10.1080/01431160902882520

[11] Ben, L., James, S. and Aber, H. (2012) Low-Cost Field Goniometer for Multiangular Reflectance Measurements. Emporia State Research Studies, 44, 1-6.

[12] Verger, A., Baret, F. and Weiss, M. (2012) A Multisensor Fusion Approach to Improve LAI Time Series. Remote Sensing of Environment, 115, 2460-2470. https://doi.org/10.1016/j.rse.2011.05.006

[13] Baret, F., Hagolle, O., Geiger, B., Bicheron, P., Miras, B., Huc, M., Berthelot, B., Niño, F., Weiss, M., Samain, O., Roujean, J.L. and Leroy, M. (2007) LAI, fAPAR and fCover CYCLOPES Global Products Derived from VEGETATION: Part 1: Principles of the Algorithm. Remote Sensing of Environment, 110, 275-286. https://doi.org/10.1016/j.rse.2007.02.018

[14] Coburn, C.A., Van Gaalen, E., Peddle, D.R. and Flanagan, L.B. (2010) Anisotropic Reflectance Effects on Spectral Indices for Estimating Ecophysiological Parameters Using a Portable Goniometer System. Canadian Journal of Remote Sensing, 36, S355-S364. https://doi.org/10.5589/m10-066

[15] Laurent, C.V., Verhoef, W., Clevers, J.W. and Schaepman, M.E. (2011) Inversion of a Coupled Canopy-Atmosphere Model Using Multi-Angular Top-of-Atmosphere Radiance Data: A Forest Case Study. Remote Sensing of Environment, 115, 2603-2612. https://doi.org/10.1016/j.rse.2011.05.016

[16] Schopfer, J., Dangel, S., Kneubühler, M. and Itten, K.L. (2008) The Improved Dual-View Field Goniometer System FIGOS. Sensors (Basel), 8, 5120-5140. https://doi.org/10.3390/s8085120

[17] Wit, E. and McClure, J. (2004) Statistics for Microarrays: Design, Analysis, and Inference. 5th Edition, John Wiley \& Sons Ltd., Chichester.

[18] Sandmeier, S.R. (2007) Acquisition of Bidirectional Reflectance Factor Data with Field Goniometers. Remote Sensing of Environment, 73, 257-269. https://doi.org/10.1016/S0034-4257(00)00102-4

[19] Biliouris, D., Verstraeten, W.W., Dutré, P., Van Aardt, J.A.N., Muys, B. and Coppin, P. (2007) A Compact Laboratory Spectro-Goniometer (CLabSpeG) to Assess the BRDF of Materials. Presentation, Calibration and Implementation on Fagus sylvatica L. Leaves. Sensors, 7, 1846-1870. https://doi.org/10.3390/s7091846

[20] Sandmeier, S., Sandmeier, W., Itten, K.I., Schaepman, M.E. and Kellenberger, T.W. (1995) The Swiss Field-Goniometer System (FIGOS). 1995 International Geoscience and Remote Sensing Symposium, Quantitative Remote Sensing for Science and Applications, Vol. 3, Firenze, 10-14 July 1995, 2078-2080. https://doi.org/10.1109/IGARSS.1995.524113

[21] Stefan, R., Sandmeier, S.R. and Klaus, I.I. (1999) A Field Goniometer System (FIGOS) for Acquisition of Hyperspectral BRDF Data. IEEE Transactions on Geoscience and Remote Sensing, 37, 978-986. https://doi.org/10.1109/36.752216

[22] Mark, C. (2000) Testing a Lisk BRDF Model with in Situ Bidirectional Reflectance Factor Measurements over Semiarid Grasslands. Remote Sensing of Environment, 74, 287-312. https://doi.org/10.1016/S0034-4257(00)00122-X

[23] Juerg, T.S., Stefan, D., Johannes, W.K., Mathias, K., Jens, N., Gabriela, S.S., Michael, E.S. and Klaus, I.I. (2004) Comparison of Field and Laboratory Spectro-Directional Measurements Using a Standard Artificial Target. In: Meynart, R., Neeck, S.P. and 
Shimoda, H., Eds., Sensors, Systems, and Next-Generation Satellites VIII, Proceedings of SPIE, Vol. 5570, SPIE, Bellingham, WA, 626-633.

[24] Jouni, I., Peltoniemi, J.P., Jyri, N., Juha, S., Risto, K., Lauri, M. and Eija, H. (2007) Bidirectional Reflectance Spectrometry of Gravel at the Sjökulla Test Field. ISPRS Journal of Photogrammetry and Remote Sensing, 62, 434-446.

https://doi.org/10.1016/j.isprsjprs.2007.07.009

[25] Dimitrios, B., Dimitry, V., Der, Z., Willem, W., Verstraeten, J.S., Bart, M., Philip, D. and Pol, C. (2009) RPV Model Parameters Based on Hyperspectral Bidirectional Reflectance Measurements of Fagussy lvatica Leaves. Remote Sensing, 1, 92-106. https://doi.org/10.3390/rs1020092

[26] Schneider, T.H, Dorigo, W.A., Huber, K. and Schneider, W. (2006) Field Goniometer Measurements for Biophysical Parameter Retrieval in Support of Chris Data Evaluations. 4th ESA CHRIS/Proba Workshop, ESRIN, Frascati, 19-21 September 2006.

[27] Gabriela, S., Ulrich, B., Michael, S., Daniel, S., Corinna, D. and Klaus, L. (2002) Evaluation of Diurnal Hyperspectral HDRF Data Acquired with the RSL Field Goniometer during the DAISEX'99 Campaign. ISPRS Journal of Photogrammetry and Remote Sensing, 57, 184-193. https://doi.org/10.1016/S0924-2716(02)00122-3 